\title{
Evaluation of Platelet Indices and Complete Blood Count in Canine Mammary Tumors
}

\author{
Zeynep Günay Uçmak ${ }_{(1)}{ }^{\prime}$ Lora Koenhemsi ${ }^{2}$, Melih Uçmak ${ }_{\circledast}{ }^{1}$, Mehmet Erman Or $_{\circledast}{ }^{2}$, \\ Özge Erdoğan Bamaç ${ }^{3}$, Hazal Öztürk Gürgen ${ }^{3}$ \& Çağla Parkan Yaramış ${ }^{4}$
}

\begin{abstract}
Background: Malignant mammary tumors in humans and bitches cause hematological disorders such as anemia, erythrocytosis, thrombocytosis, hyperproteinemia, and leucopenia. Novel studies have been conducted on the predictive and prognostic values of platelet (PLT) indices in human breast cancer (HBC). However, there is little information about the alterations in hematological parameters in canine mammary tumors (CMTs). The aims of this study were to evaluate the platelet indices and complete blood count (CBC) parameters in bitches with and without mammary tumor and to assess the above mentioned parameters with regard to histological tumor types and grades.

Materials, Methods \& Results: A total of 71 bitches were enrolled in this study. The bitches in the study group were divided into 2 groups which consisted of malignant epithelial mammary tumors (group EMT; $n=43$ ) and malignant mixed mammary tumors (group MMT; $\mathrm{n}=12$ ). Control group (group C) consisted of clinically and gynaecologically healthy 16 bitches. Blood samples were obtained to perform the CBC and PLT indices analysis. Histopathological examinations were carried out under a light microscope. Histological tumor types and malignancy grades were classified. The bitches with mammary tumor showed significantly increased PLT values and decreased hematocrit (HCT), hemoglobin (HGB) and mean corpuscular hemoglobin $(\mathrm{MCH})$ values versus the healthy ones, regardless of the tumor type. However, in comparisons with the group C, mean platelet volume (MPV) and mean corpuscular hemoglobin concentration (MCHC) values were different only in the group MMT, while plateletcrit (PCT) and mean corpuscular volume (MCV) values were different only in the group EMT. Also white blood cell (WBC), PLT and PCT values were higher than the referenced laboratory ranges in grade 3 tumors. In the presented study, MPV was considerably correlated with PLT, platelet distribution width (PDW) and PCT. Also, PCT and PLT had high sensitivity and specificity to distinct EMT and MMT from the healthy bitches.

Discussion: Microcytic and hypochromic anemia occurs due to the decrease in the amount of HGB. Levels of MCV, MCH, and $\mathrm{MCHC}$ in the HBC group were reported to be significantly lower than in humans without breast cancer. Although anemia did not occur in EMT and MMT groups, obtained significances in the HCT, HGB, MCV, MCH, and MCHC levels between the bitches with and without mammary tumor were in line with the previous reports. In this study, WBC levels in grade 3 tumors were significantly higher than grade1 tumors $(P<0.05)$. Whereas levels of WBC in grade 1 and grade 2 tumors were in referenced laboratory ranges, it was higher in grade 3. Increased level of WBC in grade 3 was supposed to be due to the rise in malignancy as previously reported. Thrombocytosis was detected in $48.83 \%$ and $41.66 \%$ of the bitches in EMT and MMT groups, respectively. The higher percentage of CMTs with thrombocytosis in this study might be due to the difference in referenced upper limit of PLT in previous studies. The elapsed time between tumor formation and clinical presentation could be another influencing factor. Although PLT and PCT values were not significant according to the histological grading in this study, both parameters were found to be higher in grade 3 than the normal reference values. Further studies conducted with higher populations may lead the differences in these parameters to significance. With the support of further studies, alterations in the above mentioned parameters in bitches may contribute in the diagnosis process, management of treatment and may constitute an easy way to have an idea about the prognosis of mammary tumors.
\end{abstract}

Keywords: bitches, grade, hematology, mammary tumor, platelet indices.

${ }^{1}$ Department of Obstetrics and Gynaecology, ${ }^{2}$ Department of Internal Medicine, ${ }^{3}$ Deparment of Pathology, Faculty of Veterinary Medicine \& ${ }^{4}$ Vocational School of Veterinary Medicine, Equine and Equine Training Program, Istanbul University-Cerrahpaşa, Avcilar, Istanbul, Turkey. CORRESPONDENCE: M. Uçmak [melih.ucmak@iuc.edu.tr]. Department of Obstetrics and Gynaecology, Faculty of Veterinary Medicine, Istanbul University-Cerrahpaşa. TR-34320 Avcilar, Istanbul, Turkey. 


\section{INTRODUCTION}

Mammary tumors are the most common neoplasms in intact bitches [33]. Although mammary tumors mostly derive from epithelial origin, there are also tumors with mixed histology that consist of epithelial and myoepithelial tissue. Epithelial tumors are often classified according to histopathologic borders and differentiation [14]. There are few mammary tumors that are entirely of mesenchymal origin [30]. Malignant mixed tumors which represent $20 \%$ to $32 \%$ of all the malignant mammary tumors consist of epithelial components and connective tissue like cells [11]. Malignant mixed tumors and carcinosarcomas are aggressive tumors, with poor prognosis [10]. Similar clinical, pathological and molecular features exist between CMTs and human breast cancer (HBC) [31]. Due to these similarities, CMTs provide an excellent model for HBC [1]. Malignant mammary tumors in humans [24] and in bitches [21] cause hematological disorders such as anemia, erythrocytosis, thrombocytosis, hyperproteinemia, and leucopenia. With the introduction of more up-to-date and better working complete blood count (CBC) devices, the roles of platelet (PLT) indices have been understood. Novel studies exist on predictive and prognostic values of PLT indices in HBC $[15,22,35]$. However, there is little information about the alterations in hematological parameters in CMTs. The aims of this study were to evaluate the PLT indices and CBC parameters in bitches with and without mammary tumor and to assess the above mentioned parameters with regard to histological tumor types and grades.

\section{MATERIALS AND METHODS}

\section{Animals}

A total of 71 bitches were enrolled in this study. The study group consisted of 55 bitches which had a tumor in a single mammary gland. Control group (Group C) consisted of clinically and gynaecologically healthy 16 bitches which were presented to the clinic for ovariohysterectomy. The ages and weights of the bitches in group $\mathrm{C}$ ranged from 2 to 9 years and from 5 to $35 \mathrm{~kg}$. The bitches in the study group were divided into 2 groups which consist of malignant epithelial mammary tumors (group EMT; $\mathrm{n}=43$ ) and malignant mixed mammary tumors (group MMT; $\mathrm{n}=12$ ). The ages and weights of the bitches in group EMT ranged from 7 to 18 years and from 5 to $50 \mathrm{~kg}$ whereas the ages and weights of the bitches in group MMT ranged from 8 to 16 and from 5 to $55 \mathrm{~kg}$.

\section{Clinical examination and surgery}

Three-view thoracic radiography ${ }^{1}$ and total blood count ${ }^{2}$ were performed in order to evaluate the preoperative anesthesia risks in all groups. Blood samples were obtained via the puncture of the vena cephalica antebrachii by using sterile 18 gauge cannula into the ethylendiaminetetra-acetic acid (EDTA) containing vacutainer tube ${ }^{3}$. Red blood cell (RBC), hemoglobin (HGB), hematocrit (HCT), white blood cell (WBC), mean corpuscular volume (MCV), mean corpuscular hemoglobin $(\mathrm{MCH})$, mean corpuscular hemoglobin concentration (MCHC), PLT, mean platelet volume (MPV), platelet distribution width (PDW), plateletcrit (PCT) measurements were incorporated into the study. Mastectomy was performed under general anesthesia for each bitch in the study group. Initially, the bitches were premedicated with atropine sulfate ${ }^{4}(0.04 \mathrm{mg} /$ $\mathrm{kg}, \mathrm{sc})$. The anesthesia was induced by $1 \%$ propofol $^{5}$ $\left(6 \mathrm{mg} / \mathrm{kg}\right.$, iv) and maintained with $3-3.5 \%$ isoflurane $^{6}$ and $1-2 \%$ oxygen combination. Anesthesia protocol was the same for the bitches in group $\mathrm{C}$.

\section{Histopathological examination}

Freshly collected canine mammary samples were fixed in $10 \%$ neutral buffered formalin, embedded in paraffin, sectioned at $4 \mu \mathrm{m}$ and stained with hematoxylin and eosin ${ }^{8}$. Histopathological examination was carried out under a light microscope ${ }^{7}$. Histological tumor types and malignancy grades were classified as reported by Goldschmidt et al. [14].

\section{Statistical analysis}

Statistical analyses were performed with SPSS 13.0 package program ${ }^{9}$. Normal distribution of data was checked by using the Shapiro-Wilk test. Oneway Anova was performed for the comparison of the groups with regard to the hematological parameters. The Pearson correlation was used to determine the relationships among the parameters evaluated. Values were given as mean \pm standard error of the mean (SEM). Receiver-operating characteristics (ROC) curve analysis was performed to determine sensitivity and specificity of PLT, MPV, PDW and PCT in group EMT and group MMT. The significance level was accepted as $P<0.05$. 


\section{RESULTS}

In group $\mathrm{C}$, the mean age and weight of the bitches were $5 \pm 0.87$ years and $15.25 \pm 2.61 \mathrm{~kg}$. The mean ages and weights of the bitches in group EMT and group MMT were $10.86 \pm 0.39$ years, $15.96 \pm 1.82 \mathrm{~kg}$ and $10.83 \pm 0.79$ years, $24 \pm 4.26 \mathrm{~kg}$; respectively. Histological tumor types in group EMT were in situ carcinoma $(\mathrm{n}$ $=2)$, ductal carcinoma $(n=1)$, simple carcinoma $(n=30)$, solid carcinoma $(n=2)$, complex carcinoma $(n=6)$ and intra-ductal papillary carcinoma $(n=2)$. The numbers of affected bitches with regard to histological grading in group EMT were grade $1(n=12)$, grade $2(n=19)$ and grade $3(n=12)$. However, group MMT had comprised of grade $2(n=5)$ and grade $3(n=7)$. Mean values and SEM of PLT indices and CBC parameters related to the groups and their significance were given in Table 1. The levels of PLT were above the referenced laboratory range
[27] in 21 bitches of group EMT and in 5 bitches of group MMT. The comparison of the histological grading in the study group (both EMT and MMT) with regard to the PLT indices and CBC parameters was presented in Table 2. Besides, histological grading in groups EMT and MMT were separately compared in terms of the PLT indices and CBC parameters. In group EMT, the mean MCHC value tended to be higher in grade 1 than grade $3(P=0.071)$ and the mean WBC value in grade 3 tended to be higher than grade $2(P=0.074)$. In group MMT, histological grades were not significantly associated with any parameters $(P$ $>0.05)$. The relationships among the PLT indices and CBC parameters were detailed in Table 3. Cut-off points, sensitivity and specificity of PLT, PDW and PCT in group EMT and group MMT were clarified in Table 4. Due to the low sensitivity and specificity percentages of MPV, the cut-off value was not specified.

Table 1. The mean values and SEM of platelet indices and complete blood count parameters and their significances related to the groups.

\begin{tabular}{|c|c|c|c|c|}
\hline Parameter & $\operatorname{EMT}(n=43)$ & $\operatorname{MMT}(\mathrm{n}=12)$ & $C(n=16)$ & $P$ \\
\hline $\mathrm{PLT}, \mathrm{K} / \mu \mathrm{L}$ & $466.37 \pm 29.59^{a}$ & $441 \pm 72.63^{\mathrm{a}}$ & $290.38 \pm 18.21^{b}$ & $* *$ \\
\hline MPV, fL & $10.54 \pm 0.27^{\mathrm{ab}}$ & $10.31 \pm 0.42^{\mathrm{a}}$ & $11.61 \pm 0.25^{\mathrm{b}}$ & $*$ \\
\hline PDW, fL & $11.90 \pm 0.24^{\mathrm{a}}$ & $12.53 \pm 0.66^{\mathrm{a}}$ & $11.28 \pm 0.41^{\mathrm{a}}$ & ns \\
\hline PCT, \% & $0.46 \pm 0.02^{\mathrm{a}}$ & $0.43 \pm 0.06^{\mathrm{ab}}$ & $0.33 \pm 0.01^{\mathrm{b}}$ & $*$ \\
\hline $\mathrm{RBC}, \mathrm{M} / \mu \mathrm{L}$ & $6.55 \pm 0.15^{\mathrm{a}}$ & $6.55 \pm 0.30^{\mathrm{a}}$ & $7.06 \pm 0.21^{\mathrm{a}}$ & $\mathrm{ns}$ \\
\hline $\mathrm{HCT}, \%$ & $41.23 \pm 1.06^{\mathrm{a}}$ & $41.64 \pm 2.32^{\mathrm{a}}$ & $46.21 \pm 1.29^{\mathrm{b}}$ & $*$ \\
\hline $\mathrm{HGB}, \mathrm{g} / \mathrm{dL}$ & $14.71 \pm 0.34^{\mathrm{a}}$ & $14.46 \pm 0.89^{a}$ & $16.84 \pm 0.47^{b}$ & $* *$ \\
\hline $\mathrm{MCV}, \mathrm{fL}$ & $62.90 \pm 0.53^{\mathrm{a}}$ & $63.30 \pm 1.15^{\mathrm{ab}}$ & $65.51 \pm 0.70^{\mathrm{b}}$ & $*$ \\
\hline $\mathrm{MCH}, \mathrm{pg}$ & $22.49 \pm 0.18^{\mathrm{a}}$ & $21.90 \pm 0.53^{a}$ & $23.86 \pm 0.19^{b}$ & $* * *$ \\
\hline $\mathrm{MCHC}, \mathrm{g} / \mathrm{dL}$ & $35.78 \pm 0.23^{\mathrm{a}}$ & $34.59 \pm 0.47^{b}$ & $36.47 \pm 0.19^{\mathrm{a}}$ & $* *$ \\
\hline $\mathrm{WBC}, \mathrm{K} / \mu \mathrm{L}$ & $14.46 \pm 1.49^{\mathrm{a}}$ & $15.71 \pm 2.78^{a}$ & $11.56 \pm 0.84^{\mathrm{a}}$ & ns \\
\hline
\end{tabular}

EMT: Epithelial mammary tumor; MMT: Malignant mammary tumor; C: Control; PLT: Platelet; MPV: Mean platelet volume; PDW: Platelet distribution width; PCT: Plateletcrit; RBC: Red blood cell; HGB: Hemoglobin; HCT: Hematocrit; WBC: White blood cell; MCV: Mean corpuscular volume; $\mathrm{MCH}$ : Mean corpuscular hemoglobin; MCHC: Mean corpuscular hemoglobin concentration; a,b: Values not sharing the same superscript in the same line were significant. *: $P<0.05 ; * *: P<0.01$; ***: $P<0.001 ;$ ns: $P>0.05$.

Table 2. The mean values and SEM of platelet indices and complete blood count parameters related to histological grading.

\begin{tabular}{|c|c|c|c|c|}
\hline Parameter & Grade $1(n=12)$ & Grade $2(n=24)$ & Grade $3(n=19)$ & $P$ \\
\hline $\mathrm{PLT}, \mathrm{K} / \mu \mathrm{L}$ & $413.92 \pm 39.78$ & $451.58 \pm 44.23$ & $502.16 \pm 52.26$ & ns \\
\hline MPV, fL & $10.81 \pm 0.60$ & $10.71 \pm 0.40$ & $10.01 \pm 0.23$ & ns \\
\hline PDW, fL & $11.56 \pm 0.59$ & $12.22 \pm 0.39$ & $12.12 \pm 0.33$ & ns \\
\hline PCT, \% & $0.42 \pm 0.02$ & $0.44 \pm 0.03$ & $0.49 \pm 0.04$ & ns \\
\hline $\mathrm{RBC}, \mathrm{M} / \mu \mathrm{L}$ & $6.75 \pm 0.25$ & $6.48 \pm 0.18$ & $6.52 \pm 0.27$ & ns \\
\hline $\mathrm{HCT}, \%$ & $42.38 \pm 1.75$ & $40.90 \pm 1.41$ & $41.17 \pm 1.88$ & ns \\
\hline $\mathrm{HGB}, \mathrm{g} / \mathrm{dL}$ & $15.47 \pm 0.56$ & $14.49 \pm 0.43$ & $14.35 \pm 0.69$ & ns \\
\hline MCV, fL & $62.75 \pm 0.88$ & $63.07 \pm 0.83$ & $63.02 \pm 0.78$ & ns \\
\hline $\mathrm{MCH}, \mathrm{pg}$ & $22.94 \pm 0.32$ & $22.41 \pm 0.30$ & $21.93 \pm 0.30$ & ns \\
\hline $\mathrm{MCHC}, \mathrm{g} / \mathrm{dL}$ & $36.59 \pm 0.41^{\mathrm{a}}$ & $35.57 \pm 0.33^{\mathrm{ab}}$ & $34.79 \pm 0.30^{\mathrm{b}}$ & $* *$ \\
\hline $\mathrm{WBC}, \mathrm{K} / \mu \mathrm{L}$ & $13.45 \pm 2.31^{\mathrm{a}}$ & $11.79 \pm 0.81^{\mathrm{ab}}$ & $19.27 \pm 3.15^{\mathrm{b}}$ & $*$ \\
\hline
\end{tabular}

RBC: Red blood cell; HGB: Hemoglobin; HCT: Hematocrit; WBC: White blood cell; MCV: Mean corpuscular volume; MCH: Mean corpuscular hemoglobin; MCHC: Mean corpuscular hemoglobin concentration; PLT: Platelet; MPV: Mean platelet volume; PDW: Platelet distribution width; PCT: Plateletcrit; ${ }^{\text {a,b }}$ : Values not sharing the same superscript in the same line were significant. $*: P<0.05 ; * *: P<0.01$; ns: $P>0.05$. 


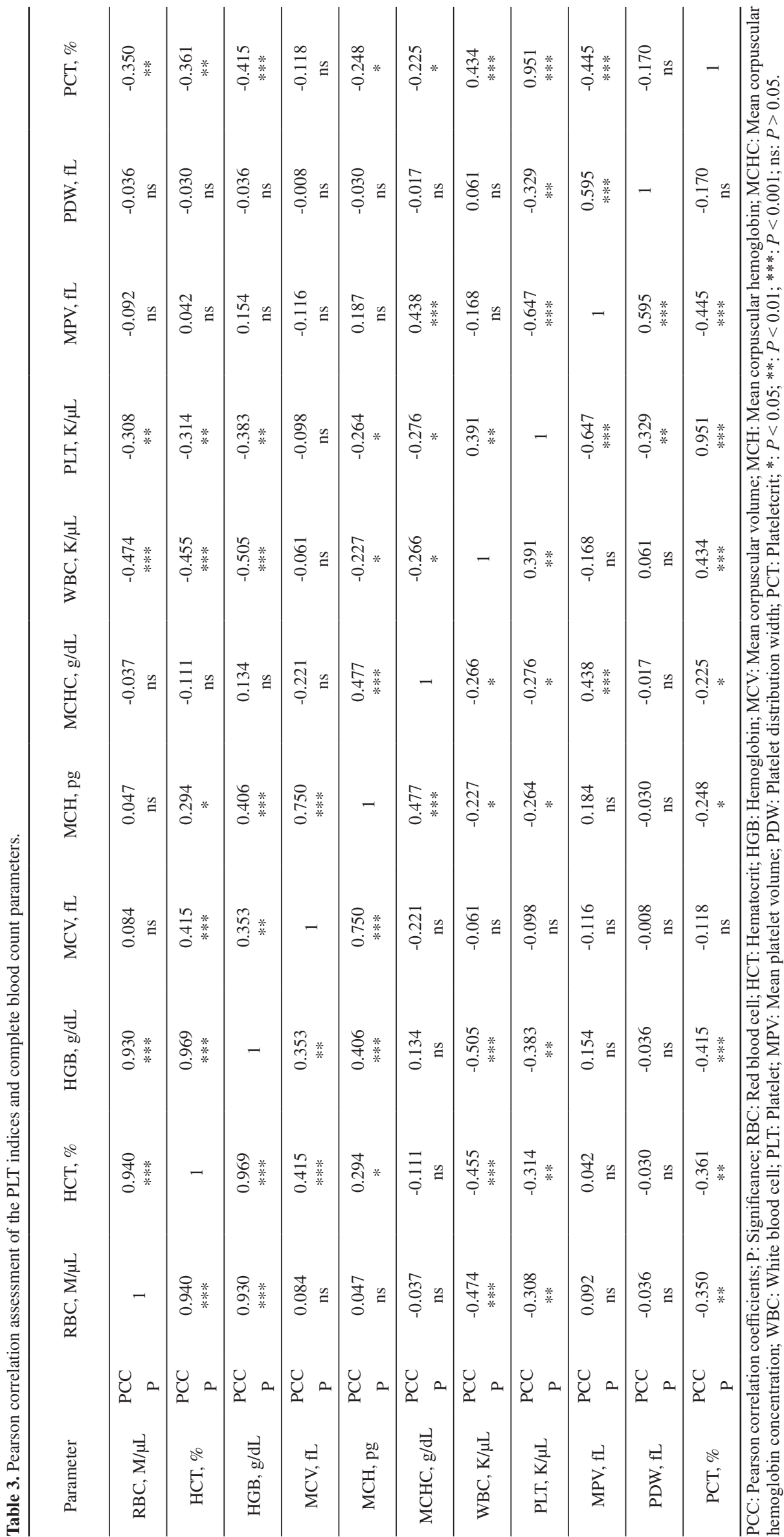


Table 4. Cut-off points, sensitivity, and specificity of PLT, PDW and PCT in group EMT and group MMT.

\begin{tabular}{ccccccc}
\hline & \multicolumn{3}{c}{ Group EMT } & \multicolumn{3}{c}{ Group MMT } \\
\hline Parameter & Cut-off point & Sensitivity $\%$ & Specificity $\%$ & Cut-off point & Sensitivity $\%$ & Specificity $\%$ \\
\hline PLT, K/ $\mu \mathrm{L}$ & 420 & 62 & 93 & 370 & 58 & 87 \\
PDW, fL & 11.3 & 60 & 68 & 11.25 & 75 & 68 \\
PCT, $\%$ & 0.4 & 60 & 81 & 0.4 & 58 & 81 \\
\hline
\end{tabular}

EMT: Epithelial mammary tumor; MMT: Malignant mammary tumor; PLT: Platelet; PDW: Platelet distribution width; PCT: Plateletcrit.

\section{DISCUSSION}

In bitches, mammary tumors are the most common neoplasms with a median age of occurrence between 9 and 11 years [9]. In this study, the mean ages of the bitches in groups EMT and MMT were similar with the previous report [9]. Anemia is one of the paraneoplastic syndromes in veterinary oncology [5] and it was positively correlated with tumor hypoxia in cancer patients [12]. Low HGB levels were correlated with higher amounts of tumor hypoxia with poorer prognosis [38]. Microcytic and hypochromic anemia occurs due to the decrease in the amount of HGB [8]. Levels of $\mathrm{MCV}, \mathrm{MCH}$, and $\mathrm{MCHC}$ in $\mathrm{HBC}$ group were reported to be significantly lower than in humans without breast cancer [28]. Although anemia had not been formed in EMT and MMT groups, obtained significances in the HCT, HGB, MCV, MCH, and MCHC levels between the bitches with and without mammary tumor were in line with the previous reports [12,28,38]. Systemic inflammatory response (SIR) affects the survival in the several forms of cancer [13]. Also, WBCs have a significant role in both SIR and mechanisms in the tumor growth and metastasis [24]. Additionally, WBC is a potential marker for predicting the progression and recurrence of many malignancies [37]. In this study, WBC level in grade 3 was significantly higher than grade1 $(P<0.05)$. Whereas levels of WBC in grade 1 and grade 2 were in referenced laboratory ranges (4.0$17.6 \times 10^{3} / \mu \mathrm{L}$ ) [27], it was higher in grade 3. Increased level of WBC in grade 3 was supposed to be due to the rise in malignancy as previously reported [24,37]. The PLT level was detected above the referenced laboratory range in 3.3\% of the bitches with mammary carcinomas [34]. Hemostatic alterations such as PLT, activated partial thromboplastin time (aPTT), prothrombin time (PT) and fibrinogen were investigated in various type of cancer in bitches and it was indicated that $26.6 \%$ of the bitches with mammary carcinoma had thrombocytosis [4]. In this study, while $100 \%$ of the bitches in group C had PLT levels within the referenced laboratory range (110-460 x $103 \mu \mathrm{L}$; [27]), 51.16\% of group EMT and $50 \%$ of group MMT were within the limits. Thrombocytosis was detected in $48.83 \%$ and $41.66 \%$ of the bitches in EMT and MMT groups, respectively. The higher percentage of CMTs with thrombocytosis in this study may be due to the difference in referenced upper limit of PLT in previous studies. Although not evaluated in the present and above mentioned studies $[4,34]$, the elapsed time between tumor formation and clinical presentation may be another influencing factor. The PLT count has predictive value in various cancer types in humans [17]. The researchers [3] evaluated the influence of cancer type on the hemostatic parameters of the dogs and they reported no significant difference between the cancer types for PLT. Although there was no significance between PLT levels among the study groups, both were significantly higher than the group C. Results of this study also showed that the predictive role of PLT could also be said for malignant CMTs. Increased levels of MPV in humans have been a predictive and prognostic factor for invasive breast cancer [15]. The mean MPV level in the control group was significantly higher than humans with lung cancer [26]. In contrast with $\mathrm{Gu}$ et al. [15] but in line with Oncel et al. [26], in this study the MPV level in group $\mathrm{C}$ was higher than in group MMT. Under normal circumstances, there is an inverse relationship between the number and volume of PLT. When PLTs decrease in number, bone marrow megakaryocytes are stimulated by thrombopoietin, and their nucleus becomes hyperlobulated, with much higher DNA content. These stimulated megakaryocytes produce larger PLTs [2]. The difference obtained between MMT and C group in this study might be due to the view that larger PLTs are more active and more responsive against endogenous and exogenous stimuli compared to smaller PLTs and they may cause consumption of these cells [16]. The PCT was investigated in various cancer types $[18,23,26,39]$. Although the researchers [26] reported 
lower PCT levels in lung cancer patients than healthy controls, high PCT levels were detected in ovarian, endometrial, and colorectal cancers [18,23,39]. In this study, while no significance was obtained between group C and group MMT in terms of PCT values, significance was determined between group $\mathrm{C}$ and group EMT. It was thought that PCT level may exhibit variable behavior in different species, cancer types and histological subtypes.

In bitches with mammary carcinomas, the PLT levels were not significantly different within the histological grades [34]. Levels of MPV [15] and PCT [35] were not significantly associated with the grading of HBC. Besides, there was no significant difference in PDW according to the stage of HBC [25]. In this study, PLT and PLT indices were not significantly different in terms of the histological grading similar with the previous reports $[15,25,34,35]$. Thrombocytosis was observed in gynaecological cancers (ovarian, endometrial, cervical) in humans associated with poor outcomes [32]. High PLT count is associated with poor survival rate in breast cancer patients [36]. PLTs influence the progression of cancer [29] and they are involved in key steps of malignancy progression [7]. The researchers [6] evaluated the value of preoperative PLT count in endometrial carcinoma patients and it was reported that PLT levels were significantly higher in grade 3 than in both grade 1 and grade 2. Although PLT and PCT values were not significant according to the histological grading in this study, both parameters were found to be higher in grade 3 than the normal reference values [20,27]. Further studies conducted with higher populations may lead the differences in these parameters to significance.

The association between MPV and hematological parameters in invasive HBCs was investigated and it was reported that MPV was significantly correlated with PLT [15]. Also, MPV was reported to be associated with PDW in an inflammatory condition such as enteritis [19]. In the presented study, MPV was considerably correlated with not only PLT but also PDW and PCT. The researchers reported that PCT and PDW were prognostic factors in HBCs due to their sensitivity and specificity
[22,35]. Similarly, in this study, PCT and PLT had high sensitivity and specificity to distinct EMT and MMT from the healthy bitches.

\section{CONCLUSION}

To the best of our knowledge, this is the first study to evaluate the PLT indices and CBC parameters in CMTs with regard to histological tumor types and grading. In conclusion, the present study showed that the bitches with mammary tumors have significantly increased PLT values and decreased HCT, HGB and $\mathrm{MCH}$ values versus the healthy ones, regardless of the tumor type. However, in comparison with the control group, MPV and MCHC values were different only in the MMT group, while PCT and MCV values were different only in the EMT group. Also, WBC, PLT and PCT values were higher than the referenced laboratory ranges in grade 3 tumors. With the support of further studies, alterations in the above mentioned parameters in bitches may contribute in the diagnosis process, management of treatment and may constitute an easy way to have an idea about the prognosis of mammary tumors.

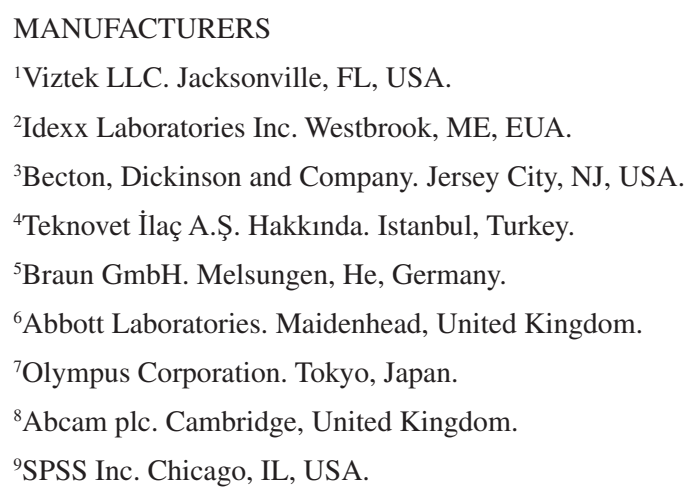

Acknowledgements. The authors thanks Prof. Dr. Bülent Ekiz for the statistical analysis.

Ethical approval. All animal procedures were carried out in accordance with the approval of the Unit Ethical Committee at Istanbul University-Cerrahpaşa Faculty of Veterinary Medicine (Approval number: 2020/37).

Declaration of interest. The authors report no conflicts of interest. The authors alone are responsible for the content and writing of the paper.

\section{REFERENCES}

1 Abdelmegeed S.M. \& Mohammed S. 2018. Canine Mammary Tumors as a Model for Human Disease. Oncology Letters. 15(6): 8195-8205. DOI: 10.3892/ol.2018.8411 
2 Alsweedan S.A., Al-Shurman A. \& Mahmoud A.S. 2008. Diagnostic Value of Platelet Indices in Children with Leukemia. Journal of Pediatric Hematology/Oncology. 30(12): 953-955. DOI: 10.1097/MPH.0b013e318182e7a9

3 Andreasen E.B., Tranholm M., Wiinberg B., Markussen B. \& Kristensen A. 2012. Haemostatic Alterations in a Group of Canine Cancer Patients Are Associated with Cancer Type and Disease Progression. Acta Veterinaria Scandinavica. 54(1): 3. DOI: 10.1186/1751-0147-54-3

4 Anjos D.S., Santilli J., Vital A.F., de Oliveira J.R., Sobreira M.F.R., Magalhães G.M., Calazans S.G. \& FonsecaAlves C.E. 2018. Evaluation of Hemostatic Parameters in Tumor-Bearing Dogs. Acta Scientiae Veterinariae. 46(1): 8. DOI: $10.22456 / 1679-9216.89004$

5 Aydın D., Olgun Erdikmen D., Ülgen S., Demirutku A. \& Durmuş D. 2011. Paraneoplastic Syndromes in Cats and Dogs. Journal of Faculty of Veterinary Medicine, Erciyes University. 8(2): 127-137.

6 Ayhan A., Bozdag G., Taskiran C., Gultekin M., Yuce K. \& Kucukali T. 2006. The Value of Preoperative Platelet Count in the Prediction of Cervical Involvement and Poor Prognostic Variables in Patients with Endometrial Carcinoma. Gynecologic Oncology. 103(3):902-905. DOI: 10.1016/j.ygyno.2006.05.034

7 Bambace N.M. \& Holmes C.E. 2011. The Platelet Contribution to Cancer Progression. Journal of Thrombosis and Haemostasis. 9(2): 237-249. DOI: 10.1111/j.1538-7836.2010.04131.x

8 Baştan I. 2013. Paraneoplastic Syndrome in Dogs. Dicle Üniversitesi Veteriner Fakültesi Dergisi. 1(4): 19-24.

9 Benavente M.A., Bianchi C. \& Aba M. 2016. Canine Mammary Tumors: Risk Factors, Prognosis and Treatments. Journal of Veterinary Advances. 6(8): 1291-1300. DOI: 10.5455/jva.20160916045115

10 Campos C.B., Lavalle G.E., Ligorio S.F., Monteiro L.N., Amorim R.L. \& Cassali G.D. 2017. Thalidomide Treatment in a Canine Mammary Gland Carcinosarcoma Presenting Pulmonary Metastasis. Advances in Animal and Veterinary Sciences. 5(3): 120-126. DOI: 10.14737/journal.aavs/2017/5.3.120.126

11 Cassali G.D., Bertagnolli A.C., Ferreira E., Damasceno K.A, Gamba C.O \& de Campos C.B 2012. Canine Mammary Mixed Tumours: A Review. Veterinary Medicine International. 2012: 274608. DOI: 10.1155/2012/274608

12 Gaspar B.L., Sharma P. \& Das R. 2015. Anemia in Malignancies: Pathogenetic and Diagnostic Considerations. Hematology. 20(1): 18-25. DOI: 10.1179/1607845414Y.0000000161

13 Giraldo N.A., Becht E., Vano Y., Sautès-Fridman C. \& Fridman W.H. 2015. The Immune Response in Cancer: From Immunology to Pathology to Immunotherapy. Virchows Archiv: An International Journal of Pathology. 467(2): 127-135. DOI: $10.1007 / \mathrm{s} 00428-015-1787-7$

14 Goldschmidt M., Pena L., Rasotto R. \& Zappulli V. 2011. Classification and Grading of Canine Mammary Tumors. Veterinary Pathology. 48(1): 117-131. DOI: 10.1177/0300985810393258

15 Gu M., Zhai Z., Huang L., Zheng W., Zhou Y., Zhu R., Shen F. \& Yuan C. 2016. Pre-Treatment Mean Platelet Volume Associates with Worse Clinicopathologic Features and Prognosis of Patients with Invasive Breast Cancer. Breast Cancer. 23(5): 752-760. DOI: 10.1007/s12282-015-0635-6.

16 Inagaki N., Kibata K., Tamaki T., Shimizu T. \& Nomura S. 2014. Prognostic Impact of the Mean Platelet Volume/ Platelet Count Ratio in Terms of Survival in Advanced Non-Small Cell Lung Cancer. Lung Cancer. 83(1): 97-101. DOI: 10.1016/j.lungcan.2013.08.020

17 Jurasz P., Alonso-Escolano D. \& Radomski M.W. 2004. Platelet-Cancer Interactions: Mechanisms and Pharmacology of Tumour Cell-Induced Platelet Aggregation. British Journal of Pharmacology. 143(7): 819-826. DOI: 10.1038/ sj.bjp.0706013

18 Karateke A., Kaplanoglu M. \& Baloglu A. 2015. Relations of Platelet Indices with Endometrial Hyperplasia and Endometrial Cancer. Asian Pacific Journal of Cancer Prevention. 16(12): 4905-4908. DOI: 10.7314/apjcp.2015.16.12.4905

19 Koenhemsi L. 2019. Determination of Platelet Count and Platelet Indices in Canine Parvoviral Enteritis. Medical Science and Discovery. 6(2): 24-26. DOI: 10.17546/msd.522081

20 Koenhemsi L., Uçmak Z.G., Uçmak M. \& Or M.E. 2020. Platelet Indices in Dogs and Cats with Pyometra. Revue Vétérinaire Clinique. 55(4): 147-150. DOI: 10.1016/j.anicom.2020.07.002

21 Lallo M.A., Ferrarias T.M., Stravino A., Rodriguez J.F.M. \& Zucare R.L.C. 2016. Hematologic Abnormalities in Dogs Bearing Mammary Tumors. Revista Brasileira de Ciência Veterinária. 23(1/2): 3-8. DOI: 10.4322/rbcv.2016.020

22 Lu Y., Cui M., Liang Z., Wang W., Jiang M., Xu M., Wu M., Shen M., Li W., Gao Y., Lian L. \& Duan W. 2019. Prognostic Values of Platelet-Associated Indicators in Advanced Breast Cancer. Translational Cancer Research. 8(4): 1326-1335. DOI: $10.21037 /$ tcr.2019.07.28 
23 Ma X., Wang Y., Sheng H., Tian W., Qi Z., Teng F. \& Xue F. 2014. Prognostic Significance of Thrombocytosis, Platelet Parameters and Aggregation Rates in Epithelial Ovarian Cancer. The Journal of Obstetrics and Gynaecology Research. 40(1): 178-183. DOI: 10.1111/jog.12151

24 Mantas D., Kostakis I.D., Machairas N. \& Markopoulos C. 2016. White Blood Cell and Platelet Indices as Prognostic Markers in Patients with Invasive Ductal Breast Carcinoma. Oncology Letters. 12(2): 1610-1614. DOI: 10.3892/ ol.2016.4760

25 Okuturlar Y., Gunaldi M., Tiken E.E., Oztosun B., Inan Y.O., Ercan T., Tuna S., Kaya A.O., Harmankaya O. \& Kumbasar A. 2015. Utility of Peripheral Blood Parameters in Predicting Breast Cancer Risk. Asian Pacific Journal of Cancer Prevention. 16(6): 2409-2412. DOI: 10.7314/apjcp.2015.16.6.2409.

26 Oncel M., Kiyici A., Oncel M., Sunam G.S., Sahin E. \& Adam B. 2015. Evaluation of Platelet Indices in Lung Cancer Patients. Asian Pacific Journal of Cancer Prevention. 16(17): 7599-7602. DOI: 10.7314/apjcp.2015.16.17.7599.

27 Plumb D.C. 2008. Reference laboratory ranges. In: Plumb's Veterinary Drug Handbook. Ames: Blackwell Publishing Professional, pp.1394-1395.

28 Rajizadeh A., Mozaffari-Khosravi H., Zavar-reza J. \& Shiryazdi SM. 2017. Comparison of Hematological Parameters, Iron Levels, and Oxidative Stress in Women with and without Breast Cancer: A Case- Control Study. Medical Journal of the Islamic Republic of Iran. 31: 114. DOI: 10.14196/mjiri.31.114

29 Reidl J., Pabinger I. \& Ay C. 2014. Platelet in Cancer and Thrombosis. Hamostaseologie. 34(1): 55-62. DOI: 10.5482/ HAMO-13-10-0054

30 Saad E.S., Milley K.M., Al-Khan A.A., Nimmo J.S., Bacci B., Tayebi M., Day M.J., Richardson S.J. \& Danks J.A. 2019. Canine Mixed Mammary Tumour as a Model for Human Breast Cancer with Osseous Metaplasia. Journal of Comparative Pathology. 156(4): 352-365. DOI: 10.1016/j.jcpa.2017.03.005

31 Sahabi K., Selvarajah G.T., Abdullah R., Cheah Y.K. \& Tan G.C. 2018. Comparative Aspects of MicroRNA Expression in Canine and Human Cancers. Journal of Veterinary Science. 19(2): 162-171. DOI: 10.4142/jvs.2018.19.2.162

32 Sharma D. \& Sing G. 2017. Thrombocytosis in Gynecological Cancers. Journal of Cancer Research and Therapeutics. 13(2): 193-197. DOI: 10.4103/0973-1482.189234

33 Sorenmo K. 2013. Canine Mammary Gland Tumors. Veterinary Clinics: Small Animal Practice. 33(3): 573-596. DOI: 10.1016/s0195-5616(03)00020-2

34 Stockhaus C., Kohn B., Rudolph R., Brunnberg L. \& Giger U. 1999. Correlation of Haemostatic Abnormalities with Tumour Stage and Characteristics in Dogs with Mammary Carcinoma. The Journal of Small Animal Practice. 40(7): 326-331. DOI: 10.1111/j.1748-5827.1999.tb03090.x

35 Takeuchi H., Noda D., Abe M., Anami K., Miyawaki M., Osoegawa A. \& Sugio K. 2020. Evaluating the Platelet Distribution Width-to-Plateletcrit Ratio as a Prognostic Marker for Patients with Breast Cancer. Anticancer Research. 40(7): 3947-3952. DOI: 10.21873/anticanres.14386

36 Taucher S., Salat A., Gnant M., Kwasny W., Mlineritsch B., Menzel R.C., Schmid M., Smola M.G., Stierer M., Tausch C., Galid A., Steger G. \& Jakesz R. 2003. Impact of Pretreatment Thrombocytosis on Survival in Primary Breast Cancer. Thrombosis and Haemostasis. 89(6): 1098-1106. PMID: 12783124

37 Templeton A.J., McNamara M.G., Šeruga B., Vera-Badillo F.E., Aneja P., Ocaña A., Leibowitz-Amit R., Sonpavde G., Knox J.J., Tran B., Tannock I.F. \& Amir E. 2014. Prognostic Role of Neutrophil-to-Lymphocyte Ratio in Solid Tumors: A Systematic Review and Meta-Analysis. Journal of the National Cancer Institute. 106(6): 1-11. DOI: 10.1093/jnci/dju124

38 Varlotto J. \& Stevenson M.A. 2005. Anemia, Tumor Hypoxemia, and the Cancer Patient. International Journal of Radiation Oncology, Biology, Physics. 63(1): 25-36. DOI: 10.1016/j.ijrobp.2005.04.049.

39 Zhu X., Cao Y., Lu P., Kang Y., Lin Z., Hao Y. \& Song Y. 2018. Evaluation of Platelet Indices as Diagnostic Biomarkers for Colorectal Cancer. Scientific Reports. 8(1): 11814. DOI: 10.1038/s41598-018-29293-X 